
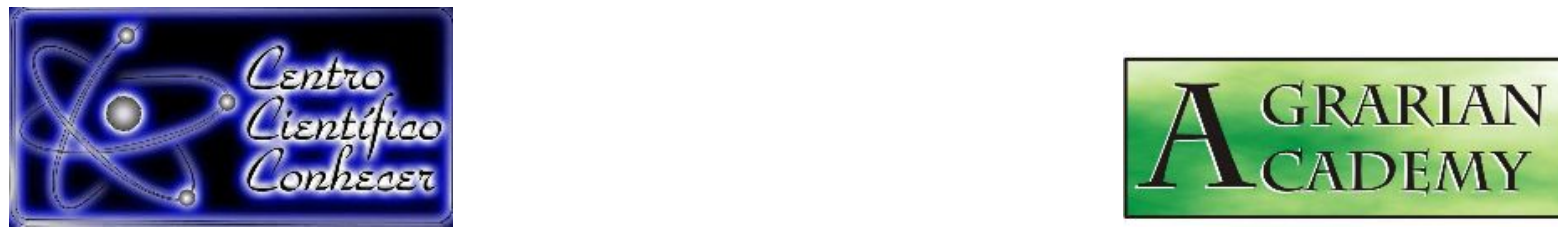

\title{
EFEITOS DO SOMBREAMENTO COM MILHO E CROTALÁRIA JUNCEA, NO CLIMA DO CRATO-CE, NO CULTIVO DA ALFACE MÔNICA
}

Raquel Rodrigues Gonçalves ${ }^{1}$, Pedro Bruno Xavier de Alcantâra'; Brendo Alves da Silva Souza"; Felipe Thomaz da Camara².

1- Graduando em Engenharia Agronômica, Bolsista do Programa de Educação Tutorial (PET) da Agronomia da Universidade Federal do Cariri (UFCA), Crato- CE, Brasil. raquel04rodrigues@hotmail.com;

2- Professor Adjunto, Universidade Federal do Cariri (UFCA), Tutor do Pet Agronomia, Crato- CE.

Recebido em: 14/07/2018 - Aprovado em: 28/07/2018 - Publicado em: 31/07/2018 DOI: 10.18677/Agrarian_Academy_2018a22

\section{RESUMO}

Este estudo objetivou verificar a influência do sombreamento na cultivar da alface Mônica, na cidade de Crato-CE, de Setembro de 2016 a março de 2017. O experimento seguiu o delineado em blocos distribuídos ao acaso, organizado em parcelas subdivididas, possuindo quatro repetições. As parcelas foram compostas pelos ciclos das plantas da alface (Primeiro, segundo e terceiro) e as subparcelas foram as plantas empregadas para fornecimento de sombra lateral dos canteiros de alface (C1 - Testemunha; C2 - Crotalária Juncea; C3 - Milho e C4-Milho + Crotalária juncea). As parcelas foram compostas por duas sequências de canteiros, distantes $1,0 \mathrm{~m}$ entre si, o método para irrigar empregado era composto por microaspersores localizados no intervalo dos canteiros $e$ as culturas para fornecimento de sombra. Avaliou-se as seguintes características: massa das plantas e das folhas, o diâmetro da parte aérea, o comprimento e a largura da maior folha, o número de folhas, o comprimento e a massa das raízes, e o diâmetro, comprimento e massa do caule. Ao analisar os resultados obtidos, foi verificado que entre os canteiros de alface sombreados e a testemunha, não houve diferença significativa, quanto aos ciclos pode-se concluir que o terceiro ciclo foi muito afetado pelos índices pluviométricos apresentados na estação, porém apresentou comportamento similar aos demais em relação às plantas empregadas para fornecimento de sombra.

PALAVRAS- CHAVE: Ciclos; Diâmetro; Folhas; Olerícola; Produção.

\section{EFFECTS OF SHADING WITH MAIZE AND CROTALARY JUNCEA, FOR THE CLIMATE CONDITIONS OF THE CRATO-CE, IN THE CULTIVATION OF MONIC LETTUCE}

\section{ABSTRACT}

This study aimed to mark the influence of shade on the Mônica nature, in the city of Crato-CE, from September 2016 to March 2017. The experiment followed the outline of random distribution blocks, organized in subdivided plots, with four replicates. The 
plots were composed along the cycle of the plants of the face (First, second and third) and as subplots were the plants for the lateral shade of lettuce corns (C1 Witness; C2 - Crotalaria Juncea; C3 - Corn and C4 - Corn + Crotalaria juncea). The plots were composed of two sequences of corners, spaced $1.0 \mathrm{~m}$ apart, the method to irrigate the teeth was composed of microsprinklers in the corner interval and shade cultures. The sequences are as follows: plant mass and leaves, shoot diameter, leaf length and width, leaf number, diameter, stem width and mass, root extension and mass. When analyzing the results obtained, it was reported that among lettuce singers and throughout the cycle was greatly affected by the rainfall levels in a window, although it presented a similar behavior to the others In relation to the plants used to provide shade.

KEYWORDS: Cycles; Sheets; Diameter; Oleraceous; Production.

\section{INTRODUÇÃO}

A alface vem se destacando nos anos mais recentes devido a crescente demanda, uma vez que o mercado exige muito desta cultura, sempre disponível e a preços acessíveis, com boa gama de variedades, custo baixo para produzir, e bons lucros obtidos com a comercialização. A alface possui grande valor econômico a nível mundial. Dados da Organização das Nações Unidas para Agricultura e Alimentação, apontam que a produção mundial de alface e chicória em 2016 foi de 26,78 milhões de toneladas (FAO, 2018).

No Brasil, está cultura encontra-se em constante crescimento. A alface se destaca por ser uma folha muito consumida no país, é a $3^{\underline{a}}$ hortaliça com maior produção volumétrica, movimentando anualmente, em média, um montante de 384,63 milhões de dólares em sua cadeia produtiva, apenas no elo correspondente as propriedades produtoras, com uma quantidade de mais de 1,7 milhão de toneladas ao ano. Na região nordeste do Brasil existe a comercialização do produto, mesmo que restringido devido às características da cultura (CNA, 2017).

Segundo Blind e Silva Filho (2015) devido à tendência de pendoar precocemente sob altas temperaturas, vem se desenvolvendo estudos acerca de cultivares as quais sejam menos propensas a este problema e alternativas de cultivo que visem reduzir o efeito negativo das temperaturas acima do tolerado pelas plantas, luminosidade, bem como precipitação sobre as plantas, porque essas condições são essenciais para o sucesso da atividade desta olerícola, principalmente em regiões tropicais.

O sombreamento da cultura é utilizado como forma de diminuir os impactos provenientes das altas temperaturas presentes no nordeste brasileiro. Conforme Seabra Júnior et al. (2012) a implementação do sombreamento é uma alternativa para minimizar os efeitos da temperatura e da luminosidade excessiva, sendo o tipo e o percentual de sombreamento determinados conforme o tipo de cultivar e condições climáticas locais.

Desta forma, o presente trabalho objetivou avaliar os efeitos do sombreamento lateral nas plantas de alface, por meio de utilização de milho e crotalária juncea como culturas fornecedoras de sombra, em três ciclos sucessivos no território do Cariri compreendido no Ceará.

\section{MATERIAL E MÉTODOS}

A pesquisa foi conduzida na área de experimentação cientifica do Centro de Ciências Agrárias e da Biodiversidade (CCAB) da Universidade Federal do Cariri 
(UFCA), localizado na cidade de Crato, Ceará, possuindo as seguintes coordenadas 7¹4'49"S, 39²2'05"W e 413 metros acima do nível do mar. A classificação do clima é Aw, seguindo o enquadramento de Köppen Alvares et al. (2013) sendo caracterizado como tropical. No inverno existe menor pluviosidade quando comparado ao verão. O Crato possui temperatura média de $25,1^{\circ} \mathrm{C}$ e pluviosidade média anual de $1.086 \mathrm{~mm}$.

O local de condução da pesquisa apresenta solo caracterizado como Argissolo Vermelho Amarelo, de textura arenosa, seguindo o modelo de classificação de média intensidade da (FUNCEME 2013). A composição química da camada de 0-20 cm foi: $\mathrm{pH}$ (1:2,5 H2O): 6,0; P (melich-1): 3,0 mg dm-3; K: 1,27 mmolc dm-3; Ca: 5,0 mmolc dm-3; Mg: 6,0 mmolc dm-3; CTC: 35,4 mmolc dm-3 e V (\%): 53.

As informações climáticas (temperatura e precipitação) no intervalo de 21 de agosto de 2016 à 19 de março de 2017 estão no Gráfico 1, fazendo referência ao espaço de tempo entre a condução dos três ciclos das plantas de alface na área da pesquisa.

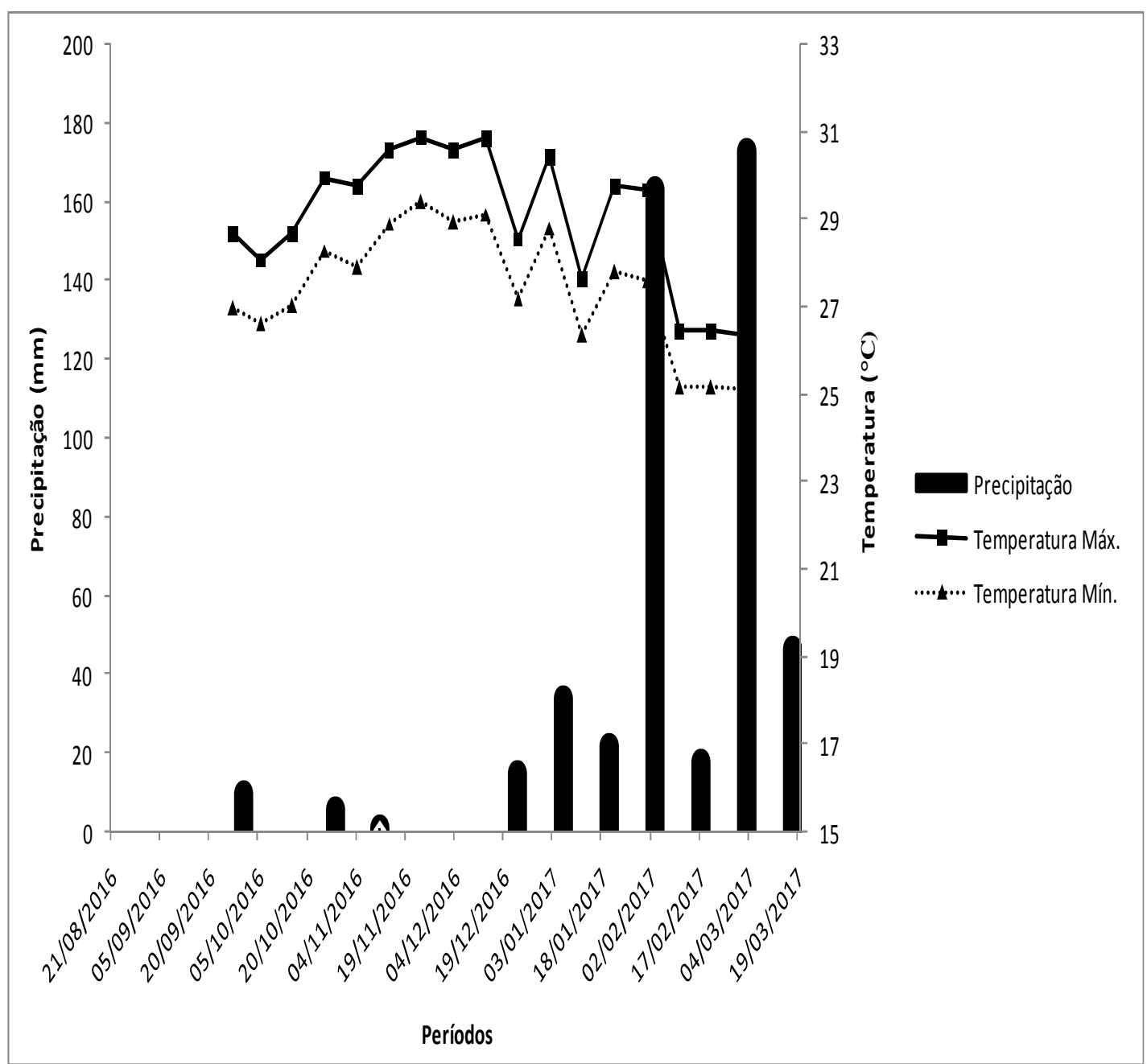

GRÁFICO 1. Temperatura máxima e mínima do $\operatorname{ar}\left({ }^{\circ} \mathrm{C}\right)$ e Precipitação $(\mathrm{mm})$, quinzenal, de 21/08/2016 a 19/03/2017, dados adaptados do INMET e FUNCEME (2017). 
A pesquisa seguiu o delineamento em blocos distribuídos ao acaso, seguindo esquema de parcelas subdivididas, possuindo quatro repetições. As parcelas foram compostas pelos ciclos das plantas de alface (Primeiro, segundo e terceiro) e as subparcelas foram as plantas empregadas para o fornecimento de sombra na lateral dos canteiros com alface (C1 - Testemunha; C2 - Crotalária Juncea; C3 - Milho e C4-Milho + Crotalária juncea).

O local de condução do experimento foi constituído por duas sequências de canteiros, distantes a 1,0 m entre si, o método de irrigação empregado era composto por microaspersores localizados no intervalo dos canteiros e as plantas para fornecimento de sombra.

Cada unidade experimental continha um canteiro medindo dois metros de comprimento por um metro de largura, a alface foi transplantada com distância de 30 $\mathrm{cm}$ entre plantas, sendo o mesmo entre fileiras, perfazendo 18 plantas por unidade experimental. Com a finalidade de realizar a análise, foram avaliadas seis plantas em cada parcela sendo estas localizadas no centro do canteiro, excluindo-se as extremidades que foram consideradas bordaduras.

Realizou-se somente uma adubação com esterco bovino, aplicando a quantidade de $5 \mathrm{~L} \mathrm{~m}^{-2}$ de canteiro, posteriormente misturando a terra do local e erguendo o canteiro com $15 \mathrm{~cm}$ de altura. Esta adubação foi realizada antes do transplante das mudas em cada um dos ciclos avaliados.

No primeiro ciclo, as plantas que foram empregadas para fornecimento de sombra tiveram a semeadura feita em 01 de setembro de 2016 em única fileira localizada lateralmente em comparação a localização do canteiro, já a crotalária juncea foi semeada de forma a atender a densidade de 40 e de 20 plantas em cada metro, cultivadas sozinhas e em consórcio com o milho, nesta ordem. Ao passo que as plantas de milho seguiram semeadura com cinco plantas a cada metro, indiferente da semeadura destas plantas ter sido sozinha ou em consórcio.

As plantas empregadas no sombreamento não receberam adubação durante a semeadura, sendo este fato limitante para o crescimento, de forma que a crotalária no instante em que a alface foi colhida possuía altura de 1,26 m, do milho de 1,20 m e do conjunto de milho com crotalária de 1,23 m.

As bandejas de 128 cédulas com a finalidade de gerar as mudas de alface, do primeiro ciclo, foram semeadas no dia 21 de setembro, enquanto o transplante foi executado em 10 de outubro de 2016, neste momento as plantas das culturas de cobertura já estavam com 40 dias de desenvolvimento e altura superior a $40 \mathrm{~cm}$. A colheita foi realizada no dia 16 de novembro de 2016, sendo feita com 56 dias posteriores a semeadura (DAS) nas bandejas.

Após o término do primeiro ciclo, as plantas empregadas no sombreamento foram trituradas em forrageira e depositadas nos canteiros equivalentes aos tratamentos, para cobertura dos mesmos, permanecendo no segundo e terceiro ciclos. O total de massa seca depositado nos canteiros de alface que utilizaram milho, crotalária e milho + crotalária foi de aproximadamente $1 \mathrm{~kg} \mathrm{~m}^{-2}$, com a testemunha, que não utilizou plantas para sombreamento permanecendo com o solo descoberto.

Para o segundo e terceiro ciclos, utilizaram-se as mesmas culturas para fornecimento de sombra lateral, as quais apresentaram menor altura na colheita do segundo ciclo em comparação a colheita do terceiro ciclo da alface. A semeadura das plantas para fornecimento de sombra foi realizada em 22 de dezembro de 2016 e permaneceram no campo até o dia 29 de março de 2017, apresentando altura de 
1,10 $\mathrm{m}$ para a crotalária, $0,90 \mathrm{~m}$ para o milho e de $0,95 \mathrm{~m}$ para o conjunto de milho + crotalária, na época da colheita do segundo ciclo da alface, que foi semeada em bandejas no dia 12 de dezembro de 2016, transplantada no dia 02 de janeiro de 2017 e colhida para análise no dia 04 de fevereiro de 2017, aos 54 DAS.

Para o terceiro ciclo, as plantas usadas para fornecer sombra já estavam com mais de um metro de altura no momento do transplantio, sendo que o plantio nas bandejas foi executado no dia 28 de janeiro de 2017, o transplante das plantas ocorreu em 15 de fevereiro de 2017 e a colheita no dia 29 de março de 2017, aos 60 DIAS, momento no qual as plantas empregadas para fornecimento de sombra atingiram a maior altura, com 2,27 m para a crotalária, $1,80 \mathrm{~m}$ para o milho e de 1,94 m para o conjunto de milho + crotalária.

Durante os três ciclos, a única prática cultural realizada foi o arranquio manual das plantas daninhas dentro dos canteiros e com enxada na área no entorno dos canteiros. Foram analisadas as variáveis: diâmetro da parte aérea, realizada no momento de coleta com fita métrica, o diâmetro do caule, após a retirada das folhas medido com um paquímetro, número de folhas, o comprimento do caule e da raiz, o comprimento e a largura da maior folha, bem como da massa da planta inteira, das folhas, do caule e da raiz, tudo aferido com o auxílio de balança semi-analítica que detém precisão de duas casas decimais em gramas.

Foram realizadas tabulação e submissão dos dados à análise de variância (ANAVA), bem como ao teste de Tukey a $5 \%$ de probabilidade para fins de comparação das médias, através do programa SISVAR 5.3 (FERREIRA, 2010).

\section{RESULTADOS E DISCUSSÃO}

$\mathrm{Na}$ tabela 1 averígua-se que não ocorreram interações significativas no tocante a totalidade das variáveis analisadas. A ANAVA realizada constatou a existência de significância a 1\% para os ciclos nas características, diâmetro da parte aérea, massa da planta e das folhas, largura da folha e número de folhas, além de significância na ordem de $5 \%$ no que se refere ao comprimento das folhas.

Para todas as variáveis, o terceiro ciclo apresentou resultados inferiores aos demais ciclos. As diferenças ocorreram devido as altas precipitações pluviométricas no período (Gráfico 1), provocando menor desenvolvimento das plantas. No geral, as hortaliças têm desenvolvimento e rendimento influenciado pelas condições de clima e umidade do solo. A deficiência de água no solo é, frequentemente, o fator mais limitante para a obtenção de altos rendimentos. O excesso pode, também, ser prejudicial por favorecer a proliferação de doenças (LUCIETTI 2013).

Estes problemas acarretados pelo excedente de umidade ocorreram mais no terceiro ciclo, sendo que os dois primeiros não foram afetados por altas precipitações pluviométricas, obtendo assim melhores resultados. Somente as variáveis, largura da folha e número de folhas apresentaram diferenças estatísticas quando analisadas no teste de Tukey. Segundo Lima et al. (2016) durante a condução de estudos avaliando diferentes cultivares da alface crespa (Amanda, Invicta, Brida, Cristal e Verônica), nas mesmas condições climáticas, segundo a classificação de KOPPEN, verificaram que não houve diferenças significativas para as variáveis diâmetro da planta, número de folhas e massa verde total. As plantas apresentaram diâmetro médio de $31,65 \mathrm{~cm}$ e em média 22 folhas por planta, valores superiores ao deste trabalho. 
TABELA 1. Síntese da análise de variância e do teste de médias para a massa das plantas (MP), a massa das folhas (MF), o diâmetro da parte aérea (DA), o comprimento da folha (CF), a largura da folha (LF) e o número de folhas (№F).

\begin{tabular}{|c|c|c|c|c|c|c|c|}
\hline \multirow{2}{*}{$\begin{array}{l}\text { Fontes de } \\
\text { Variação }\end{array}$} & \multirow{2}{*}{ G.L } & \multicolumn{6}{|c|}{ Quadrados Médios } \\
\hline & & MP & MF & DA & CF & LF & №F \\
\hline Bloco & 3 & $\begin{array}{l}2105 \\
\text { NS }\end{array}$ & $\begin{array}{c}1214 \\
\text { NS }\end{array}$ & $\begin{array}{c}18,12 \\
\text { NS }\end{array}$ & $\begin{array}{l}0,48 \\
\text { NS }\end{array}$ & 0,61 NS & $3,86^{N S}$ \\
\hline Ciclo (C) & 2 & $\underset{* \star}{49402}$ & 33301 & $178,5^{* *}$ & 20,04 * & $175,1^{* *}$ & $411,8^{* *}$ \\
\hline Resíduo (a) & 6 & 1127 & 718 & 12,27 & 2,14 & 3,57 & 4,71 \\
\hline $\begin{array}{l}\text { Cultura } \\
\text { Sombreamento } \\
\text { (CS) }\end{array}$ & 3 & $1827^{*}$ & 1062 ** & $\begin{array}{c}2,90 \\
\text { NS }\end{array}$ & $\begin{array}{c}2,27 \\
\text { NS }\end{array}$ & $3,59^{\mathrm{NS}}$ & $6,48^{N S}$ \\
\hline Interação $C^{*}$ CS & 6 & $868^{N S}$ & $495^{N S}$ & $\begin{array}{c}5,76 \\
\text { NS }\end{array}$ & $\begin{array}{c}3,06 \\
\text { NS }\end{array}$ & $1,83^{N S}$ & $1,94^{N S}$ \\
\hline Resíduo (b) & 27 & 411 & 229 & 7,22 & 1,49 & 1,59 & 3,32 \\
\hline CV $1(\%)$ & - & 28,22 & 28,30 & 15,26 & 9,81 & 15,30 & 14,22 \\
\hline \multirow[t]{2}{*}{ CV $2(\%)$} & & 17,06 & 16,02 & 11,71 & 8,18 & 10,22 & 11,95 \\
\hline & \multicolumn{7}{|c|}{ Teste de Médias de Tukey $(p<0,05)$} \\
\hline \multirow[t]{2}{*}{ Tratamentos } & & MP & MF & DA & $\mathrm{CF}$ & LF & №F \\
\hline & \multicolumn{3}{|c|}{-------- g -------- } & \multicolumn{3}{|c|}{----- cm --- } & Unidade \\
\hline \multicolumn{8}{|l|}{ Ciclo } \\
\hline Primeiro & & $140,9 \mathrm{a}$ & $121,1 \mathrm{a}$ & $24,3 \mathrm{a}$ & $15,7 \mathrm{a}$ & $15,5 \mathrm{a}$ & $19,5 \mathrm{a}$ \\
\hline Segundo & & $160,1 \mathrm{a}$ & $120,9 a$ & $25,4 \mathrm{a}$ & $15,5 \mathrm{a}$ & $12,7 \mathrm{~b}$ & $16,6 \mathrm{~b}$ \\
\hline Terceiro & & $55,7 \mathrm{~b}$ & $42,0 \mathrm{~b}$ & $19,1 \mathrm{~b}$ & $13,6 \mathrm{~b}$ & $8,9 \mathrm{c}$ & $9,6 \mathrm{c}$ \\
\hline \multicolumn{8}{|c|}{ Cultura Sombreamento } \\
\hline Sem & & $130,6 \mathrm{a}$ & $104,1 \mathrm{a}$ & 22,3 & 14,4 & 12,9 & 16,2 \\
\hline Crotalária & & $\begin{array}{c}128,5 \\
a b\end{array}$ & $\begin{array}{c}101,3 \\
a b\end{array}$ & 23,5 & 15,4 & 12,7 & 14,6 \\
\hline Milho & & 106,7 b & $85,3 \mathrm{~b}$ & 23,0 & 14,8 & 12,1 & 15,3 \\
\hline $\begin{array}{c}\text { Milho e } \\
\text { Crotalária }\end{array}$ & & $\begin{array}{c}110,0 \\
a b\end{array}$ & $88,0 \mathrm{ab}$ & 23,1 & 15,1 & 11,7 & 14,8 \\
\hline
\end{tabular}

Com relação ao sombreamento com as culturas, somente foram significativas as variáveis: massa das plantas e folhas, logrando os resultados mais positivos no ambiente que não possuía plantas para sombreamento lateral. Estes resultados podem indicar que o sombreamento lateral, por proporcionar sombra nos canteiros 
pelo início da manhã e final da tarde, períodos com temperatura mais amena, não proporcionam o conforto térmico desejado pela cultura, pois no momento de maiores temperaturas durante o dia, as plantas permanecem descobertas. Ferreira et al. (2014) constataram que em condições de menor temperatura do ar e maior aporte de luminosidade acontece o favorecimento do desempenho da alface.

Estes resultados contrastam com os de Arruda et al. (2014) que testaram três tipos de hortaliças com sombreamento, constatando que os canteiros testemunhas apresentaram melhor desenvolvimento, fenômeno este condicionado ao fato de que a condução do experimento foi em um período de baixa incidência solar.

No tocante ao número de folhas, não foi observada diferença significativa em decorrência das plantas empregadas para fornecimento de sombreamento com milho, crotalaria e milho com crotalaria e a testemunha, resultado este, semelhante ao encontrado por Ricardo et al. (2014) que analisando sombreamento e espaçamento em diversas variedades de alface, constataram que o número de folhas apresentado era semelhante. Porém, Silva et al. (2015) testando alfaces crespas da cultivar vera em sistemas de sombreamento com casa de vegetação, tela e espaldeira com maracujazeiro e a testemunha, perfazendo percentuais de sombra de $35 \%, 50 \%, 52 \%$ e $0 \%$, nos períodos chuvoso e de estiagem, obtiveram as maiores médias no tocante a massa de folhas no ambiente de cultivo protegido em ambos os climas.

$\mathrm{Na}$ Tabela 2, percebe-se que somente a variável comprimento do caule demonstrou interação significativa, com a mesma sendo discutida na tabela 3. Dentre os resultados obtidos, constatou-se que o ciclo obteve diferenças significativas para o diâmetro, massa do caule, comprimento e massa das raízes (Tabela 2). O terceiro ciclo expôs resultados inferiores, sendo similar ao primeiro ciclo apenas no tocante a massa do caule. Estes resultados ocorreram devido às baixas precipitações durante os dois primeiros ciclos, sendo possível controlar o fornecimento da água por meio da irrigação, em contrapartida no terceiro ciclo houve interferência das precipitações constantes (Gráfico 1).

Resende et al. (2017) demonstraram em estudos realizados no Submédio do Vale do São Francisco, avaliando no período com chuva e no seco, que o excesso de água compromete o desenvolvimento caulinar e radicular da alface. Resultados semelhantes ao de Santos et al. (2015) estudando o crescimento da Alface sob influência da irrigação e adubação, concluíram que quanto maior a quantidade de água no solo, mas susceptível encontra-se a planta, não se desenvolvendo satisfatoriamente.

TABELA 2. Síntese da análise de variância e do teste de médias para o diâmetro do caule (DC), o comprimento do caule (CC), a massa do caule (MC), o comprimento da raiz $(\mathrm{CR})$ e a massa das raízes (MR).

\begin{tabular}{|c|c|c|c|c|c|c|}
\hline \multirow{2}{*}{$\begin{array}{l}\text { Fontes de } \\
\text { Variação }\end{array}$} & \multirow{2}{*}{ G.L. } & \multicolumn{5}{|c|}{ Quadrados Médios } \\
\hline & & DC & $\mathrm{CC}$ & $\mathrm{MC}$ & CR & MR \\
\hline Bloco & 3 & $0,159^{\mathrm{NS}}$ & $0,54^{\mathrm{NS}}$ & $122^{N S}$ & $4,53^{N S}$ & ${ }_{13,1} \mathrm{NS}$ \\
\hline Ciclo (C) & 2 & $4,84 * \star$ & 14,30 * & $2833^{* *}$ & 209 ** & 815 ** \\
\hline Resíduo (a) & 6 & 0,07 & 1,95 & 67 & 8,08 & 15,45 \\
\hline $\begin{array}{c}\text { Cultura } \\
\text { Sombreamento }\end{array}$ & 3 & $0,046^{N S}$ & 3,62 * & $102^{N S}$ & 8,23 * & $37,6^{\mathrm{NS}}$ \\
\hline
\end{tabular}


(CS)

\begin{tabular}{|c|c|c|c|c|c|c|}
\hline $\begin{array}{c}\text { Interação } C^{*} C S \\
\text { Resíduo (b) }\end{array}$ & $\begin{array}{c}6 \\
27\end{array}$ & $\begin{array}{c}0,045^{\mathrm{NS}} \\
0,042\end{array}$ & $\begin{array}{c}3,85^{* *} \\
0.91\end{array}$ & $62^{N S}$ & $\begin{array}{c}4,10^{\mathrm{NS}} \\
2.47\end{array}$ & $31,9^{\mathrm{NS}}$ \\
\hline CV $1(\%)$ & & 17,85 & 26,70 & 33,72 & 28,27 & 33,94 \\
\hline \multirow[t]{2}{*}{ CV $2(\%)$} & & 13,81 & 18,27 & 24,35 & 15,63 & 39,69 \\
\hline & \multicolumn{6}{|c|}{ Teste de Médias de Tukey $(p<0,05)$} \\
\hline \multirow[t]{2}{*}{ Fatores } & & DC & $C c^{1}$ & MC & $\mathrm{CR}$ & MR \\
\hline & & \multicolumn{2}{|c|}{----- cm ----- } & G & $\mathrm{cm}$ & G \\
\hline $\begin{array}{l}\text { Ciclo }(\mathrm{C}) \\
\text { Primeiro } \\
\text { Segundo } \\
\text { Terceiro }\end{array}$ & & $\begin{array}{l}1,82 \mathrm{a} \\
1,80 \mathrm{a} \\
0,86 \mathrm{~b}\end{array}$ & $\begin{array}{l}- \\
- \\
-\end{array}$ & $\begin{array}{l}19,9 \mathrm{~b} \\
39,2 \mathrm{a} \\
13,7 \mathrm{~b}\end{array}$ & $\begin{array}{c}12,5 \mathrm{a} \\
11,8 \mathrm{a} \\
5,9 \mathrm{~b}\end{array}$ & $\begin{array}{c}18,4 \mathrm{a} \\
12,1 \mathrm{~b} \\
4,2 \mathrm{c}\end{array}$ \\
\hline $\begin{array}{l}\text { Cultura } \\
\text { Sombreamento } \\
\text { (CS) }\end{array}$ & & & & & & \\
\hline $\begin{array}{l}\text { Sem } \\
\text { Crotalária } \\
\text { Milho }\end{array}$ & & $\begin{array}{l}1,57 \\
1,50 \\
1,46\end{array}$ & $\begin{array}{l}- \\
-\end{array}$ & $\begin{array}{l}26,5 \\
27,0 \\
21,4\end{array}$ & $\begin{array}{l}9,8 \mathrm{ab} \\
11,2 \mathrm{a} \\
9,4 \mathrm{~b}\end{array}$ & $\begin{array}{c}13,7 \\
11,1 \\
9.5\end{array}$ \\
\hline $\begin{array}{l}\text { Milho e } \\
\text { Crotalária }\end{array}$ & & 1,43 & - & 22,1 & $9,7 a b$ & 12,1 \\
\hline
\end{tabular}

Médias seguidas pela mesma letra minúscula na coluna, não diferem entre si pelo teste de Tukey a $5 \%$ de probabilidade. ${ }^{* *}$ : significativo $(P<0,01)$; *: significativo $(P<0,05)$; NS: não significativo; CV\%: coeficiente de variação.

Não foram apresentadas as médias em virtude da interação significativa, com os dados sendo apresentados na tabela de desdobramento da interação.

Quanto ao efeito das plantas empregadas para fornecimento de sombra, afere-se que apenas o comprimento das raízes teve diferença significativa $(p<0,05)$, com maior tamanho para as alfaces cultivadas sob influência do sombreamento usando a crotalária. Este resultado foi diferente do obtido por Gazolla-Neto et al. (2013) que ao pesquisarem os efeitos da luminosidade no desenvolvimento de tomate, e a relação parte área e raiz, concluíram que quanto maior a luminosidade, maior o período de desenvolvimento da raiz. Todavia, trabalhos realizados por Diamante et al. (2013) com alface lisa em diversos ambientes em Cáceres-MT, demonstraram que os ambientes sombreados com telas de 30 e $50 \%$ e termorefletora $50 \%$ proporcionaram os maiores comprimentos médios de caule e raiz.

$\mathrm{Na}$ tabela 3 está o desdobramento da interação entre os ciclos e as plantas empregadas no sombreamento lateral para a variável comprimento do caule. Ao analisar o efeito dos ciclos sobre as culturas, ficou evidente que o primeiro ciclo demonstrou valores superiores nos tratamentos sem sombreamento e o de milho conjuntamente com crotalária como fornecedores de sombra. 
TABELA 3: Interação entre os fatores ciclo e culturas de sombreamento para a variável comprimento do caule da alface $(\mathrm{cm})$.

\begin{tabular}{cccc}
\hline Culturas de & \multicolumn{3}{c}{ Ciclo } \\
\cline { 2 - 4 } Sombreamento & Primeiro & Segundo & Terceiro \\
\hline Sem & $6,5 \mathrm{abA}$ & $4,4 \mathrm{aB}$ & $3,2 \mathrm{bB}$ \\
Crotalária & $5,2 \mathrm{bA}$ & $4,4 \mathrm{aA}$ & $3,4 \mathrm{abA}$ \\
Milho & $5,7 \mathrm{bA}$ & $5,4 \mathrm{aA}$ & $6,0 \mathrm{aA}$ \\
Milho e Crotalária & $7,8 \mathrm{aA}$ & $5,0 \mathrm{aB}$ & $4,8 \mathrm{abB}$
\end{tabular}

Médias seguidas pela mesma letra minúscula nas colunas e maiúscula nas linhas, não diferem estatisticamente entre si segundo o teste de TuKey a $5 \%$ de probabilidade.

Com relação ao efeito das plantas empregadas para sombreamento em cada ciclo, o emprego de milho conjuntamente com crotalária apresentou maiores valores na totalidade dos ciclos, porém as variações foram pequenas entre as culturas avaliadas. Segundo Resende et al. (2008) o tamanho de caule para a comercialização de alface não deve ultrapassar $9,0 \mathrm{~cm}$ de comprimento, pois é um dos fatores cruciais para a comercialização, uma vez que as alfaces com grandes caules apresentam tendência ao pendoamento, ficando leitosas e amargas. Os resultados coincidem ainda com os obtidos por Cruz et al. (2012) que enquadraram as alfaces produzidas como aptas para a comercialização, uma vez que, apresentassem o caule dentro dos limites estabelecidos para o comércio e sem indícios de pendoamento.

\section{CONCLUSÃO}

Ao analisar os resultados obtidos, foi verificado que os canteiros de alface sombreados em relação a testemunha, não demonstraram diferença significativa. Quanto aos ciclos, pode-se concluir que o terceiro foi muito afetado pelos índices pluviométricos apresentados na estação, não podendo assim concluir o efeito de forma precisa, quando comparado com os demais ciclos.

\section{AGRADECIMENTOS}

À Universidade Federal do Cariri (UFCA) pela disponibilização de bolsas de estudo por meio do Programa de Educação Tutorial (Pet) da Agronomia, que possibilitaram a execução desta pesquisa.

\section{REFERENCIAS}

ALVARES, C. A.; STAPE, J. L.; SENTELHAS, P. C.; GONÇALVES, J. L. M.; SPAROVEK, G. Koöppen's climate classification map for Brazil. Meteorologische Zeitschrift, Berlim, v. 22, n. 6, p. 711-728, 2013.

ARRUDA, E. S.; OLIVEIRA, W. P.; GHARIB, N. F. S.; ZANELLA, M. S.; REIS, R. C.; FONSECA, T. P. de L.; BORSATO, A. V.; FEIDEN, A.. Alface, rúcula e manjericão consorciados, sombreados ou não, com e sem adubação orgânica, em sistemas de transição agroecológica no Assentamento 72 - Ladário, MS. Cadernos de Agroecologia - ISSN 2236-7934, v.9, n.1, 2014. Disponível em < revistas.abaAGRARIAN ACADEMY, Centro Científico Conhecer - Goiânia, v.5, n.9; p. 2202018 
agroecologia.org.br/index.php/cad/article/view/1552>. Acessado em 20 de janeiro de 2018.

BLIND, A. D.; SILVA FILHO, D. F. Desempenho produtivo de cultivares de alface americana na estação seca da amazônica central. Bioscience Journal, v. 31, n. 2, p. 404- 414, mar/abr 2015. DOI: http://dx.doi.org/10.14393/BJ-v31n2a2015-22352. Acessado em 15 de abril de 2018.

\section{CNA: Mapeamento e Quantificação da Cadeia Produtiva das Hortaliças.} Disponível em:< http://www.cnabrasil.org.br/sites/default/files/sites/default/files/uploads/mapeamento e_quantificacao_da_cadeia_de_hortalicas.pdf >. Acessado em 10 de julho de 2018.

CRUZ, T. P.; JUNGER, L. A.; RABELLO, L. K. C.; SILVA, L. G.; PASSOS, R. R.; Desempenho Agronômico de Cultivares de Alface para as Condições edafoclimáticas da região de Alegre - ES. Revista Nucleus, v.9, n.2, p.43-50, 2012. DOI: http://dx.doi.org/10.3738/nucleus.v9i2.694. Acessado em 15 de abril de 2018.

DIAMANTE, M. S.; SEABRA JÚNIOR, S.; INAGAKI, A. M.; SILVA, M. B.; DALLACORT, R. Produção e resistência ao pendoamento de alfaces tipo lisa cultivadas sob diferentes ambientes. Revista Ciência Agronômica, v. 44, n. 1, p. 133-140, 2013. Disponível em <ccarevista.ufc.br > Capa > v. 44, n. 1 (2013) , Diamante>. Acessado em 15 de abril de 2018.

FAOSTAT. 2018. Production. Disponível em <http://faostat.fao.org >. Acessado em 10 de julho 2018.

FERREIRA, D.F. Sisvar: a computer statistical analysis system. Ciência e Agrotecnologia, v.35, p.1039-1042, 2010. Disponível em < http://www.scielo.br/scielo.php?script=sci_arttext\&pid=S1413-70542011000600001 >. Acessado em 20 de abril de 2018.

FERREIRA, R.L.F.; ALVES, A.S.S.C.; ARAÚJO NETO, S.E.; KUSDRA, J.F.; REZENDE, M.I.F.L. Produção orgânica de alface em diferentes épocas de cultivo e sistemas de preparo e cobertura de solo. Bioscience Journal, v.30, p.1017-1023, 2014. Disponível < www.seer.ufu.br > Home > Vol 30, No 4 (2014) , Ferreira>. Acessado em 20 de abril de 2018.

FUNCEME. Levantamento de reconhecimento de média intensidade dos solos da Mesoregião do Sul Cearense / Fundação Cearense de Meteorologia e Recursos Hídricos. Fortaleza, 2013.

http://www.funceme.br/app/calendario/produto/macrorregioes/media/trimestral> .Acessado em 31 de janeiro de 2018.

FUNCEME. Fundação Cearense de Meteorologia e Recursos Hídricos. Indices pluviométricos no Cariri 2016-2017. Disponível em < http://www.funceme.br/app/calendario/produto/macrorregioes/media/trimestral>. Acessado em 31 de janeiro de 2018. 
GAZOLLA-NETO, A.; AUMONDE, T. Z.; OLSEN, T. P. D.; VILLELA, F. A. Ação dos níveis de luminosidade sobre o crescimento de plantas de Maria -pretinha (Solanum Americanum Mill.). Revista brasileira de Biociências., Porto Alegre, v.11, n.1, p. 8892, Jan/Mar. 2013. Disponível em < www.ufrgs.br/seerbio/ojs/index.php/rbb/article/view/2403>. 31 de janeiro de 2018.

INMET. Instituto Nacional de Metereologia Dados meteorológicos no Cariri 20162017. Disponível em <http://www.inmet.gov.br/portal/>. Acessado em: 31 de janeiro de 2018.

LIMA, J. C. S.; SOUSA, L. M.; MOTA, J. H.; RESENDE, G. M.; YURI, J. E. Desempenho de cultivares de alface do grupo crespa em Jataí-GO. XX Encontro Latino Americano de Iniciação Científica, XVI Encontro Latino Americano de PósGraduação e VI Encontro de Iniciação à Docência - Universidade do Vale do Paraíba. 2016. Disponível em < https://www.alice.cnptia.embrapa.br/bitstream/doc/1069390/1/Milanez2016.pdf >. Acessado em: 03 de Fevereiro de 2018.

LUCIETTE, D. Irrigação de Hortaliças. Boletim Didático no 88 "Produção orgânica de hortaliças no litoral sul catarinense, 2013. Disponível em < http://www.epagri.sc.gov.br/?page_id=214>. Acessado em: 03 de Fevereiro de 2018.

RESENDE, G. A.; YURI, J. E.; COSTA, N. D.; GOMES, A. S.; MOTA, J. H. Desempenho produtivo de genótipos de alface crespa no Submédio do Vale do São Francisco. Scientia Plena 13, 110201, v. 13.m;11. 2017. Doi: 10.14808/sci.plena.2017.110201. Acessado em 02 de abril de 2018.

RESENDE, G. M.; YURI, J. E.; MOTA, J. H.; SOUZA, R. J. Resposta da alface tipo americana a doses e épocas de aplicação de molibdênio em cultivo de inverno. Revista Ciência e Agrotecnologia, v. 32, n. 1, p. 143-148, 2008. Doi http://dx.doi.org/10.1590/S1413-70542008000100021. Acessado em 20 de abril de 2018

SANTOS, M. A L.,; SANTOS ,D. P.; MENEZES, S. M. .; LIMA, D. F.; SILVA J. P. V. Produção da cultura da alface (lactuta sativa l.) em função das lâminas de irrigação e tipos de adubos. Ciência Agrícola, Rio Largo, v. 13, n. 1, p. 33-39, 2015. DOI: http://dx.doi.org/10.28998/rca.v13i1.1652. Acessado em 02 de abril de 2018.

RICARDO, A. S. VARGAS, P. F.; FERRARI, S.; PAVARINI, G. M. P. Telas de sombreamento no desempenho de cultivares de alface. Nucleus, Ituverava, v. 11, n. 2, p. 433-442, 2014. DOI: 10.3738/1982.2278.1375. Acessado em 02 de abril de 2018

SEABRA JÚNIOR, S.; NEVES, S. M. A. S.; NUNES, M. C. M.; INAGAKI, A. M.; SILVA, M. B.; RODRIGUES, C.; DIAMANTE, M. S. Cultivo de alface em Cáceres MT: perspectivas e desafios. Disponível em < www.revistas2.uepg.br > Capa > v. 8, n. 1 (2012) > Seabra Junior > Revista Conexão, v. 8, n. 1, p. 130-137, 2012. Acessado em 02 de abril de 2018. 
SILVA, E. M. N. C. de P. da; FERREIRA, R. L. F.; RIBEIRO, A. M. A. de S.; ARAÚJO NETO, S. E. de; KUSDRA, J. F. Desempenho agronômico de alface orgânica influenciado pelo sombreamento, época de plantio e preparo do solo no Acre. Pesquisa Agropecuária Brasileira, Brasília, DF, v. 50, n. 6, p. 468-474, jun. 2015. DOI: 10.1590/S0100-204X2015000600005. Acessado em 02 de abril de 2018 